\title{
Rethinking metabotropic glutamate receptor 5 pathological findings in psychiatric disorders: implications for the future of novel therapeutics
}

\author{
Kelly A Newell ${ }^{1,2^{*}}$ and Natalie Matosin ${ }^{1,2}$
}

\begin{abstract}
Background: Pharmacological modulation of metabotropic glutamate receptor 5 (mGluR5) is of marked interest as a novel therapeutic mechanism to treat schizophrenia and major depression. However, the status of mGluR5 in the pathophysiology of these disorders remains unknown.

Discussion: The majority of studies in the schizophrenia post-mortem brain indicate that total mGluR5 expression is unaltered. However, close examination of the literature suggests that these findings are superficial, and in actuality, a number of critical factors have not yet been considered; alterations may be highly dependent on brain region, neuronal population or molecular organisation in specific cellular compartments. A number of genetic knockout studies (mGluR5, Norbin, Homer1 etc.) continue to lend support to a role of mGluR5 in the pathology of schizophrenia, providing impetus to explore the regulation of mGluR5 beyond total mGluR5 protein and mRNA levels. With regards to major depression, preliminary evidence to date shows a reduction in total mGluR5 protein and mRNA levels; however, as in schizophrenia, there are no studies examining mGluR5 function or regulation in the pathological state. A comprehensive understanding of mGluR5 regulation in major depression, particularly in comparison to schizophrenia, is crucial as this has extensive implications for mGluR5 targeting novel therapeutics, especially considering that opposing modulation of mGluR5 is of therapeutic interest for these two disorders.

Summary: Despite the complexities, examinations of post-mortem human brain provide valuable insights into the pathologies of these inherently human disorders. It is important, especially with regards to the identification of novel therapeutic drug targets, to have an in depth understanding of the pathophysiologies of these disorders. We posit that brain region- and cell type-specific alterations exist in mGluR5 in schizophrenia and depression, with evidence pointing towards altered regulation of this receptor in psychiatric pathology. We consider the implications of these alterations, as well as the distinction between schizophrenia and depression, in the context of novel mGluR5 based therapeutics.
\end{abstract}

Keywords: Metabotropic glutamate receptor, mGlu, mGluR5, GRM, Schizophrenia, Depression, Post-mortem human brain, Novel antipsychotic, Novel antidepressant, Glutamate

\section{Background}

Metabotropic glutamate receptor subtype 5 (mGluR5) is an exciting novel drug target for the treatment of psychiatric disorders including schizophrenia and major depression $[1,2]$. While the monoaminergic systems (e.g. dopamine, serotonin, norepinephrine) are the main therapeutic targets

\footnotetext{
*Correspondence: knewell@uow.edu.au

${ }^{1}$ Centre for Translational Neuroscience, Faculty of Science, Medicine and Health and Illawarra Health and Medical Research Institute, University of Wollongong, Wollongong, NSW 2522, Australia

${ }^{2}$ Schizophrenia Research Institute, Darlinghurst, NSW 2010, Australia
}

of current drugs used to treat schizophrenia and major depression, evidence suggests that the glutamatergic system and the $\mathrm{N}$-methyl-D-aspartate receptor (NMDAR) in particular, play a key role in the underlying pathophysiology of these disorders, at least in a subset of patients [3-6]. Targeting the glutamatergic NMDAR is therefore considered a novel treatment strategy for these disorders. Accordingly, NMDAR agonists such as d-serine show therapeutic potential for the treatment of schizophrenia [7], whilst the NMDAR antagonist ketamine shows rapid antidepressant effects in patients with treatment-resistant depression [8,9]. In both cases however, NMDAR-targeting drugs are 
confounded, specifically by high dose requirements and the associated risk of excitotoxicity in the case of agonists [7], and psychotomimetic effects, addictive properties and cognitive decline in the case of antagonists [10-13]. As a result of these confounds, the metabotropic glutamate receptors have been identified as a possible avenue to regulate glutamatergic transmission, while minimising the unwanted effects of targeting the NMDAR directly $[2,14]$. mGluR5 is of particular interest as it shares a structural and functional link with the NMDAR, but unlike the NMDAR it is localised in more selective brain regions where it fine-tunes glutamatergic transmission [1].

mGluR5 positive allosteric modulators (PAMs) upregulate NMDAR function [15], whilst mGluR5 antagonists and negative allosteric modulators (NAMs) downregulate NMDAR activity [16]. These agents therefore have the potential to treat NMDAR hypofunction and hyperfunction states associated with schizophrenia and major depression respectively. In spite of this exciting possibility, the success of novel mGluR5-based therapeutics is dependent on the status of mGluR5 in these disorders. Conflicting data between human pathophysiological studies, genetic studies and animal studies make it unclear whether mGluR5 is indeed altered in these pathologies and what implications this has for novel mGluR5 based therapeutics.

\section{Discussion \\ Neuropathological findings and considerations Protein studies}

Post-mortem analyses of human brain tissue from psychiatric patients provide valuable insight into the potential pathophysiology of these disorders. Often however, findings in post-mortem human brain are inconsistent with findings in more mechanistic studies such as animal- and/ or cell- based studies, highlighting the complexities of these psychopathologies. We have recently reviewed the literature with regards to examination of mGluR5 in schizophrenia [1]. Three out of four studies examining mGluR5 protein in post-mortem brain samples from schizophrenia subjects (number of subjects ranging from 9 to 37) identified no change in mGluR5 protein (monomer) levels in the prefrontal cortex (PFC), specifically Brodmann's areas (BA) $9,10,11,32$ and 46 as well as the caudate, putamen and nucleus accumbens [17-19]. In contrast to these findings, Fatemi and colleagues [20] recently reported a large reduction in mGluR5 protein (monomer) levels in the PFC (BA9) and lateral cerebellum of subjects with schizophrenia compared to controls $(n=15-20)$. Collectively, these findings raise the strong probability that alterations to mGluR5 in schizophrenia are brain region-specific and possibly cohort specific. This reinforces the importance of replication of findings in adjacent brain regions and independent cohorts and raises the notion that it is likely that
mGluR5-based therapeutics will mediate region-specific effects as well as individual-specific effects depending on the underlying neuropathology.

In major depression, mGluR5 monomer protein levels have been reported to be reduced in the lateral cerebellum [20] and prefrontal cortex (BA10) [21] using two different cohorts $(n=15)$. While this might suggest less heterogeneity of changes in this disorder, the findings should be deemed as preliminary until additional brain regions are examined and findings further replicated in independent cohorts. An important way forward for both schizophrenia and major depression will be to identify these cohort specific changes in mGluR5, as well as other markers, in living patients. The detection of peripheral biomarkers, such as singlenucleotide polymorphisms, that have associations with symptoms and brain pathology (for example, see $[5,22])$, may pave the way for an individualised treatment approach.

A fundamental issue confounding the interpretation of these aforementioned immunoblot studies is that the majority have focused on mGluR5 in the monomer form. Mature functional mGluR5s exist in a disulphide-linked dimer complex $[23,24]$ and can only be activated by agonists when in this dimer form [23]. Thus, alterations in monomers alone may not have functional significance. While one study reported no change in mGluR5 dimer levels in the PFC (BA9) and lateral cerebellum in schizophrenia and major depression [20], the use of reducing conditions (5\% $\beta$-mercaptoethanol, which breaks disulphide links) would have interfered with the dimerized status of mGluR5. It is therefore unlikely that total dimers were indeed measured and rather these measures were an artefact of the experimental procedure, whereby the ratio of monomers and dimers is reflective of the amount of reducing agent used rather than a physiological indication. There are no reported investigations of mGluR5 dimer measures in non-reducing conditions in schizophrenia or depression, however altered dimerization of another mGluR, mGluR3, has been found in the PFC of schizophrenia subjects [25]. It is crucial to take these experimental variables into account for future mGluR5 immunoblot studies, and to determine whether dimer assembly is disrupted in these neuropathologies, as this would render mGluR5 present, but inactive, thereby having implications for the novel class of mGluR5-targeting therapeutics. While mGluR5 monomers are considered non-functional as they cannot be activated by agonists, a recent report suggests that mGluR5 monomers are able to couple to G-proteins upon activation with a PAM [23]. However more research is required to determine if mGluR5 dimers are altered in these psychiatric pathologies and what impact this has on the effectiveness of mGluR5 allosteric agents [26]. 


\section{Receptor binding studies}

Another valuable approach to understanding mGluR5 in psychiatric pathology and its potential as a therapeutic target is the use of radiolabeled drugs that target the therapeutic binding site of interest. We have recently reported no change in binding to the MPEP site of mGluR5 in the post-mortem dorsolateral PFC of schizophrenia patients [17]. We have also since found unaltered mGluR5 binding in the anterior cingulate cortex of schizophrenia, major depression and bipolar subjects in the Stanley Neuropathology Consortium (unpublished observations). Considering many novel mGluR5 drugs target the MPEP site, our findings suggest that this binding site is accessible in these disorders, at least in the dorsolateral PFC and anterior cingulate cortex. While these are the only studies to have examined mGluR5 binding in schizophrenia, Deschwanden et al. [21] reported region-specific reductions in $\left[{ }^{11} \mathrm{C}\right]$ ABP688 in-vivo binding to the MPEP site in the PFC, insula, and parts of the parietal and temporal cortices in living patients with depression. These alterations were associated with depressive symptom severity. Considering Deschwanden and colleagues also reported reductions in mGluR5 protein in the PFC in major depression (in a separate post-mortem cohort) [21], it is possible that these reductions in binding and protein represent a reduction in overall mGluR5 numbers in the PFC in depression. Notably, in line with our observations, no significant change in binding was reported in the anterior cingulate cortex [21]. The assessment of binding specifically to membrane bound mGluR5 and the affinity of novel mGluR5 targeting drugs to binding sites in the brains of patients with schizophrenia and depression will aid in understanding the potential of these drugs for the treatment of psychiatric disorders. While assessment of the MPEP binding site offers insight into the binding kinetics of mGluR5 drugs that target this site, it must be noted that there is a family of mGluR5 allosteric modulators that do not bind to this site [27-29], and currently there are no radioligands available to directly assess the density and affinity of these nonMPEP sites.

\section{mRNA studies}

Although mRNA analyses do not directly equate to functional protein expression [30], examination of mRNA offers several advantages. Firstly, it allows for analyses of amino acid sequences that are highly specific to the molecule or isoform of interest. Secondly, to gain an understanding of underlying mechanisms of any changes in protein expression (for example whether they may be the result of changes in rate of synthesis), examination of mRNA expression is essential. Most recently, it was reported that there was no change in mGluR5(pan) mRNA in the PFC(BA9), together with a reduction in mGluR5 (pan) mRNA in the lateral cerebellum in schizophrenia
[20]. This same study found reduced mGluR5 protein in both the cerebellum and PFC, indicating possible deficits in mGluR5 synthesis in the cerebellum, but posttranscriptional modifications in the PFC. Consistent with this, four previous studies found no change in mGluR5 mRNA in the PFC (BA9/10), as well as the thalamus or hippocampus in schizophrenia [31-34]. One study did however report an increase in mGluR5 mRNA expression in the PFC (BA11; $\mathrm{n}=7-10$ ), which was specific to cortical layer III [34], a layer concerned with cortico-cortical projections and that is particularly implicated in schizophrenia pathophysiology [35]. It should therefore be considered that alterations in mGluR5 mRNA are not only brain regionspecific, but may also exist specifically in selective neuronal populations in the diseased brain, and analyses of total neuron populations may therefore conceal pathological alterations. With regards to major depression, preliminary studies suggest concordant reductions in mRNA and protein in post-mortem brain samples. Fatemi et al. [20] recently reported a reduction in mGluR5(pan) mRNA in the lateral cerebellum in major depression, consistent with their finding of reduced mGluR5 protein in this same region. This suggests that a reduction in mGluR5 production may occur, at least in this brain region, in major depression. To our knowledge, there are no other studies examining mGluR5 mRNA in major depression to shed light on the mechanism and extent of mGluR5 alterations in this disorder.

\section{Further considerations}

When approaching mGluR5 post-mortem findings in the context of future therapies, there has been minimal consideration of the structural complexity of this receptor. To date, mGluR5a, b, and d isoforms have been identified. These isoforms differ in their developmental profile, brain region localisation, and length of their c-terminus $[1,36,37]$. While mGluR5a and mGluR5b share similar pharmacological profiles they have opposing functions, at least in development, where mGluR5a inhibits and mGluR5b promotes neurite outgrowth [37]. Compared to mGluR5a and b, the mGluR5d isoform has increased sensitivity to desensitisation and has a shorter intracellular c-terminus by a significant 267 amino acids [36]; consequently mGluR5d has less interaction with scaffolding molecules that modulate the mGluR5/NMDAR complex (e.g. Homer), and other endogenous molecules that ensure its trafficking and cell surface localisation. This is important to consider, especially in the context of schizophrenia where the majority of studies indicate no change in overall mGluR5 levels; there may in reality be altered regulation, trafficking or recycling of mGluR5 or altered receptor-receptor interactions. For example, Homer, Norbin (neurochondrin) and Tamalin (GRASP1) act as chaperones to increase cell surface localisation of mGluR5. Homer and Norbin knockout mice 
show a schizophrenia-like behavioural phenotype [38,39], suggesting there may be deficits in membrane-bound localisation of mGluR5 in schizophrenia. Supporting this hypothesis, the mGluR5 GRM5 gene has recently been suggested as one of the top candidate genes for schizophrenia vulnerability $[40,41]$, with exome sequencing of multiplex pedigrees reporting disruption to the mGluR5/Tamalin association [40]. Consistent with this notion, mGluR5 knockout mice and mice treated with mGluR5 antagonists also demonstrate schizophrenia-like behaviours (and interestingly antidepressant behaviours, as discussed below) [1,42]. While these mGluR5 regulatory molecules have not been considered in the context of depression, Homer 1 has been implicated in the aetiology of major depression through a genome wide association study [43], suggesting possible disruptions to mGluR5 trafficking and/or mGluR5/NMDAR interactions in this disorder also.

\section{Opposing glutamatergic dysregulation in schizophrenia} and depression: Implications for novel mGluR5 therapeutics mGluR5 PAMs have shown promise in preclinical rodent models for the treatment of schizophrenia [1]. mGluR5 PAMs, such as CDPPB and more recently VU0364289, demonstrated the ability to attenuate phencyclidine and amphetamine-induced hyperlocomotion, social interaction deficits, prepulse inhibition deficits and importantly, cognitive deficits (which are largely untreated by current antipsychotics) $[1,44]$. While the development of mGluR5 PAMs have faced issues with regards to solubility and oral bioavailability, a new generation of PAMs appear to have overcome these issues [45-47]. In contrast, mGluR5 NAMs, including MPEP and MTEP, have shown antidepressant properties in rodent models, including reduced immobility time in forced swim and tail suspension tests, key tests of antidepressant efficacy in rodent models [48-50]. However, some mGluR5 NAMs have also shown the ability to produce psychotomimetic side effects in rodent models, similar to the NMDAR antagonist ketamine [51]. More recent drug design has resulted in the development of mGluR5 NAMs that appear to lack this psychotomimetic property [47].

While the glutamatergic system is implicated in the pathophysiologies of both schizophrenia and major depression, the use of mGluR5 PAMs for the treatment of schizophrenia and NAMs for the treatment of depression, suggests opposing disturbances of the glutamatergic system in these disorders. Although the data for mGluR5 in the schizophrenia brain is conflicting across studies $[1,20]$ (possibly as a result of region-specific pathology), a decline in mGluR5 in depression has now been replicated in three cohorts $[20,21]$. However, negative modulation of mGluR5 has been reported to have therapeutic efficacy in preclinical (rodent) models of depression [9,52]. In addition,
NMDAR antagonists, such as ketamine, demonstrate antidepressant properties in treatment resistant patients [10]. From the outset, the use of these therapies might indicate a hyperglutamatergic state or specific NMDAR hyperfunction in depression, suggesting that the mGluR5 reduction seen in patients with depression represents an endogenous compensatory response, and that the use of mGluR5 NAMs may act to further assist this mGluR5 downregulation. This is supported by findings of increased glutamate levels in the brains of some patients with depression [4,53-55]. As the results of clinical trials for mGluR5 NAMs in depression are not yet available, the therapeutic effects remain to be seen. It is likely that the incorporation of mGluR5-based therapeutics will be individualized depending on symptom profile and individual pathology.

The issues raised here are not limited to schizophrenia and major depression. Glutamatergic dysfunction is also implicated in other neuropsychiatric disorders including anxiety and Fragile X Syndrome. mGluR5 NAMs prevent behavioural phenotypes in animal models of these disorders [56-58]. mGluR5 NAMs including Fenobam and AFQ056 have progressed to clinical trials where they showed therapeutic effects for the treatment of anxiety and Fragile X Syndrome [59-61]. However there were reports of psychotomimetic effects following chronic treatment in some patients [59]. In addition, a recent study provides evidence that patient response to these mGluR5 NAMs may depend on individual pathophysiology [61]. This demonstrates, despite some limitations which are being considered in current drug design [62], that this class of drugs has the potential to progress into clinical therapeutics. mGluR5 PAMs on the other hand are yet to reach clinical trials.

\section{Summary}

We suggest that, despite post-mortem studies largely indicating no involvement of mGluR5 in the pathology of schizophrenia, and preliminary evidence suggesting it is down-regulated in major depression, that there is evidence in both pathologies of altered regulation of this receptor, possibly in a brain region- and cell typespecific manner. In spite of the rapid movement to develop mGluR5 pharmaceutical modulators, there has been very limited investigation into the function and regulation of mGluR5 at the genetic, mRNA and protein levels in the pathological post-mortem human and animal paradigms [63]. Only with this knowledge will we be able to tailor novel therapeutics to treat these diseases. It is likely that mGluR5-based therapeutics will be much individualised depending on symptom profile. Pharmacogenomics or peripheral biomarkers may help to identify the patients that would suit mGluR5-modulation as a therapy option. 


\section{Abbreviations}

BA: Brodmann's area; mGluR5: Metabotropic glutamate receptor subtype 5; NAM: Negative allosteric modulator; NMDAR: N-methyl-D-aspartate receptor; PAM: Positive allosteric modulator; PFC: Prefrontal cortex.

\section{Competing interests}

The authors declare that they have no competing interests.

\section{Authors' contributions}

KAN and NM drafted the manuscript. Both authors read and approved the final manuscript.

\section{Authors' information}

KAN is a Senior Lecturer in the Faculty of Science, Medicine and Health, at the University of Wollongong, Australia. NM is a doctoral candidate in the Faculty of Science, Medicine and Health, at the University of Wollongong, Australia. KN and NM are both affiliated scientists of the Schizophrenia Research Institute, Australia. NM is supported by an Australian Rotary Health lan Scott Scholarship.

Received: 2 October 2013 Accepted: 21 January 2014

Published: 28 January 2014

\section{References}

1. Matosin N, Newell KA: Metabotropic glutamate receptor 5 in the pathology and treatment of schizophrenia. Neurosci Biobehav Rev 2013, 37:256-268.

2. Krivoy A, Fischel T, Weizman A: The possible involvement of metabotropic glutamate receptors in schizophrenia. Eur Neuropsychopharmacol 2008, 18:395-405.

3. Huang C-C, Wei I-H, Huang C-L, Chen K-T, Tsai M-H, Tsai P, Tun R, Huang $\mathrm{K}-\mathrm{H}$, Chang $\mathrm{Y}-\mathrm{C}$, Lane $\mathrm{H}-\mathrm{Y}$, Tsai GE: Inhibition of glycine transporter-I as a novel mechanism for the treatment of depression. Biol Psychiatry 2013, 74:734-741.

4. Tokita K, Yamaji T, Hashimoto K: Roles of glutamate signaling in preclinical and/or mechanistic models of depression. Pharmacol Biochem Behav 2012, 100:688-704.

5. Weickert CS, Fung SJ, Catts VS, Schofield PR, Allen KM, Moore LT, Newell KA, Pellen D, Huang X-F, Catts SV, Weickert TW: Molecular evidence of $\mathrm{N}$-methyl-D-aspartate receptor hypofunction in schizophrenia. Mol Psychiatry 2013, 18:1185-1192.

6. Geddes AE, Huang XF, Newell KA: Reciprocal signalling between NR2 subunits of the NMDA receptor and Neuregulin1 and their role in schizophrenia. Prog Neuropsychopharmacol Biol Psychiatry 2011, 4:896-904

7. Labrie V, Roder JC: The involvement of the NMDA receptor d-serine/glycine site in the pathophysiology and treatment of schizophrenia. Neurosci Biobehav Rev 2010, 34:351-372.

8. Berman RM, Cappiello A, Anand A, Oren DA, Heninger GR, Charney DS, Krystal JH: Antidepressant effects of ketamine in depressed patients. Biol Psychiatry 2000, 47:351-354.

9. Hashimoto K, Malchow B, Falkai P, Schmitt A: Glutamate modulators as potential therapeutic drugs in schizophrenia and affective disorders. Eur Arch Psychiatry Clin Neurosci 2013, 263:367-377.

10. Murrough JW, Wan L-B, lacoviello B, Collins KA, Solon C, Glicksberg B, Perez AM, Mathew SJ, Charney DS, losifescu DV, Burdick KE: Neurocognitive effects of ketamine in treatment-resistant major depression: association with antidepressant response. Psychopharmacology (Berl) 2014, 231:481-488.

11. Malhotra AK, Pinals DA, Adler CM, Elman I, Clifton A, Pickar D, Breier A: Ketamine-induced exacerbation of psychotic symptoms and cognitive impairment in neuroleptic-free schizophrenics. Neuropsychopharmacology 1997, 17:141-150.

12. Lahti AC, Koffel B, Laporte D, Tamminga CA: Subanesthetic doses of ketamine stimulate psychosis in schizophrenia. Neuropsychopharmacology 1995, 13:9-19.

13. Morgan CJA, Curran HV, (iscd) the ISC on D: Ketamine use: a review. Addiction 2012, 107:27-38.

14. Witkin J, Marek G, Johnson B, Schoepp D: Metabotropic glutamate receptors in the control of mood disorders. CNS Neurol Disord - Drug Targets 2007, 6:87-100

15. Uslaner JM, Parmentier-Batteur S, Flick RB, Surles NO, Lam JSH, McNaughton $\mathrm{CH}$, Jacobson MA, Hutson PH: Dose-dependent effect of CDPPB, the
mGluR5 positive allosteric modulator, on recognition memory is associated with GluR1 and CREB phosphorylation in the prefrontal cortex and hippocampus. Neuropharmacology 2009, 57:531-538.

16. Attucci S, Carlá V, Mannaioni G, Moroni F: Activation of type 5 metabotropic glutamate receptors enhances NMDA responses in mice cortical wedges. Br J Pharmacol 2001, 132:799-806.

17. Matosin N, Frank E, Deng C, Huang X-F, Newell KA: Metabotropic glutamate receptor 5 binding and protein expression in schizophrenia and following antipsychotic drug treatment. Schizophr Res 2013, 146:170-176.

18. Corti C, Xuereb JH, Crepaldi L, Corsi M, Michielin F, Ferraguti F: Altered levels of glutamatergic receptors and $\mathrm{Na}+/ \mathrm{K}+$ ATPase- $\alpha 1$ in the prefrontal cortex of subjects with schizophrenia. Schizophr Res 2011, 128:7-14.

19. Gupta DS, McCullumsmith RE, Beneyto M, Haroutunian V, Davis KL, Meador Woodruff $\mathrm{JH}$ : Metabotropic glutamate receptor protein expression in the prefrontal cortex and striatum in schizophrenia. Synapse 2005, 57:123-131.

20. Fatemi SH, Folsom TD, Rooney RJ, Thuras PD: mRNA and protein expression for novel GABAA receptors $\theta$ and $\rho 2$ are altered in schizophrenia and mood disorders; relevance to FMRP-mGluR5 signaling pathway. Transl Psychiatry 2013, 3:e271.

21. Deschwanden A, Karolewicz B, Feyissa AM, Treyer V, Ametamey SM, Johayem A, Burger C, Auberson YP, Sovago J, Stockmeier CA: Reduced metabotropic glutamate receptor 5 density in major depression determined by [11C] ABP688 PET and postmortem study. Am J Psychiatry 2011, 168:727-734

22. Egan MF, Straub RE, Goldberg TE, Yakub I, Callicott JH, Hariri AR, Mattay VS, Bertolino A, Hyde TM, Shannon-Weickert C, Akil M, Crook J, Vakkalanka RK, Balkissoon R, Gibbs RA, Kleinman JE, Weinberger DR: Variation in GRM3 affects cognition, prefrontal glutamate, and risk for schizophrenia. Proc Natl Acad Sci U S A 2004, 101:12604-12609.

23. El Moustaine D, Granier S, Doumazane E, Scholler P, Rahmeh R, Bron P, Mouillac $B$, Banères J-L, Rondard $P$, Pin J-P: Distinct roles of metabotropic glutamate receptor dimerization in agonist activation and G-protein coupling. Proc Natl Acad Sci U S A 2012, 109:16342-16347.

24. Romano C, Yang W-L, O'Malley KL: Metabotropic glutamate receptor 5 Is a disulfide-linked dimer. J Biol Chem 1996, 271:28612-28616.

25. Corti C, Crepaldi L, Mion S, Roth AL, Xuereb JH, Ferraguti F: Altered dimerization of metabotropic glutamate receptor 3 in schizophrenia. Biol Psychiatry 2007, 62:747-755.

26. Wootten D, Christopoulos A, Sexton PM: Emerging paradigms in GPCR allostery: implications for drug discovery. Nat Rev Drug Discov 2013, 12:630-644.

27. O'Brien JA, Lemaire W, Wittmann M, Jacobson MA, Ha SN, Wisnoski DD, Lindsley CW, Schaffhauser HJ, Rowe B, Sur C, Duggan ME, Pettibone DJ, Conn PJ, Williams DL Jr: A novel selective allosteric modulator potentiates the activity of native metabotropic glutamate receptor subtype 5 in Rat forebrain. J Pharmacol Exp Ther 2004, 309:568-577.

28. Rodriguez AL, Zhou Y, Williams R, David Weaver C, Vinson PN, Dawson ES, Steckler T, Lavreysen H, Mackie C, Bartolomé JM, Macdonald GJ, Scott Daniels J, Niswender CM, Jones CK, Jeffrey Conn P, Lindsley CW, Stauffer SR: Discovery and SAR of a novel series of non-MPEP site $\mathrm{mGlu}_{5}$ PAMs based on an aryl glycine sulfonamide scaffold. Bioorg Med Chem Lett 2012, 22:7388-7392.

29. Hammond AS, Rodriguez AL, Townsend SD, Niswender CM, Gregory KJ, Lindsley CW, Conn PJ: Discovery of a novel chemical class of mGlu 5 allosteric ligands with distinct modes of pharmacology. ACS Chem Neurosci 2010, 1:702-716.

30. Greenbaum D, Colangelo C, Williams K, Gerstein M: Comparing protein abundance and mRNA expression levels on a genomic scale. Genome Biol 2003, 4:117.

31. Ohnuma T, Tessler S, Arai H, Faull RLM, McKenna PJ, Emson PC: Gene expression of metabotropic glutamate receptor 5 and excitatory amino acid transporter 2 in the schizophrenic hippocampus. Mol Brain Res 2000, 85:24-31.

32. Richardson-Burns SM, Haroutunian V, Davis KL, Watson SJ, Meador-Woodruff $\mathrm{JH}$ : Metabotropic glutamate receptor mRNA expression in the schizophrenic thalamus. Biol Psychiatry 2000, 47:22-28.

33. Volk DW, Eggan SM, Lewis DA: Alterations in metabotropic glutamate receptor $1 \mathrm{a}$ and regulator of $\mathrm{G}$ protein signaling 4 in the prefrontal cortex in schizophrenia. Am J Psychiatry 2010, 167:1489-1498.

34. Ohnuma T, Augood SJ, Arai H, McKenna PJ, Emson PC: Expression of the human excitatory amino acid transporter 2 and metabotropic glutamate receptors 3 and 5 in the prefrontal cortex from normal individuals and patients with schizophrenia. Mol Brain Res 1998, 56:207-217. 
35. Lewis DA, Glantz LA, Pierri JN, Sweet RA: Altered cortical glutamate neurotransmission in schizophrenia: evidence from morphological studies of pyramidal neurons. Ann N Y Acad Sci 2003, 1003:102-112.

36. Malherbe P, Kew JNC, Richards JG, Knoflach F, Kratzeisen C, Zenner M-T, Faull RLM, Kemp JA, Mutel V: Identification and characterization of a novel splice variant of the metabotropic glutamate receptor 5 gene in human hippocampus and cerebellum. Mol Brain Res 2002, 109:168-178.

37. Mion S, Corti C, Neki A, Shigemoto R, Corsi M, Fumagalli G, Ferraguti F: Bidirectional regulation of neurite elaboration by alternatively spliced metabotropic glutamate receptor 5 (mGluR5) isoforms. Mol Cell Neurosci 2001, 17:957-972.

38. Wang $H$, Westin L, Nong $Y$, Birnbaum S, Bendor J, Brismar H, Nestler E, Aperia A, Flajolet M, Greengard P: Norbin is an endogenous regulator of metabotropic glutamate receptor 5 signaling. Science 2009, 326:1554-1557.

39. Szumlinski KK, Lominac KD, Kleschen MJ, Oleson EB, Dehoff MH, Schwarz MK, Schwartz MK, Seeburg PH, Seeberg PH, Worley PF, Kalivas PW: Behavioral and neurochemical phenotyping of Homer1 mutant mice: possible relevance to schizophrenia. Genes Brain Behav 2005, 4:273-288.

40. Timms AE, Dorschner MO, Wechsler J, Choi KY, Kirkwood R, Girirajan S, Baker C, Eichler EE, Korvatska O, Roche KW, Horwitz MS, Tsuang DW: Support for the $\mathrm{N}$-methyl-D-aspartate receptor hypofunction hypothesis of schizophrenia from exome sequencing in multiplex families. JAMA Psychiatry 2013, 70:582-590.

41. Ayalew M, Le-Niculescu H, Levey DF, Jain N, Changala B, Patel SD, Winiger $E_{1}$ Breier A, Shekhar A, Amdur R, Koller D, Nurnberger II, Corvin A, Geyer M, Tsuang MT, Salomon D, Schork NJ, Fanous AH, O'Donovan MC, Niculescu $A B$ : Convergent functional genomics of schizophrenia: from comprehensive understanding to genetic risk prediction. Mol Psychiatry 2012, 17:887-905

42. Gray L, van den Buuse M, Scarr E, Dean B, Hannan AJ: Clozapine reverses schizophrenia-related behaviours in the metabotropic glutamate receptor 5 knockout mouse: association with N-methyl-D-aspartic acid receptor up-regulation. Int J Neuropsychopharmacol 2009, 12:45-60.

43. Rietschel M, Mattheisen M, Frank J, Treutlein J, Degenhardt F, Breuer R, Steffens M, Mier D, Esslinger C, Walter H, Kirsch P, Erk S, Schnell K, Herms S, Wichmann H-E, Schreiber S, Jöckel K-H, Strohmaier J, Roeske D, Haenisch B, Gross M, Hoefels S, Lucae S, Binder EB, Wienker TF, Schulze TG, Schmäl C, Zimmer A, Juraeva D, Brors B, et al: Genome-wide association-, replication-, and neuroimaging study implicates HOMER1 in the etiology of major depression. Biol Psychiatry 2010, 68:578-585

44. Gregory KJ, Herman EJ, Ramsey AJ, Hammond AS, Byun NE, Stauffer SR, Manka JT, Jadhav S, Bridges TM, Weaver CD, Niswender CM, Steckler T, Drinkenburg WH, Ahnaou A, Lavreysen H, Macdonald GJ, Bartolomé JM, Mackie C, Hrupka BJ, Caron MG, Daigle TL, Lindsley CW, Conn PJ, Jones CK: $\mathrm{N}$-aryl piperazine metabotropic glutamate receptor 5 positive allosteric modulators possess efficacy in preclinical models of NMDA hypofunction and cognitive enhancement. J Pharmacol Exp Ther 2013, 347:438-457.

45. Gastambide F, Gilmour G, Robbins TW, Tricklebank MD: The $\mathrm{mGlu}_{5}$ positive allosteric modulator LSN2463359 differentially modulates motor, instrumental and cognitive effects of NMDA receptor antagonists in the rat. Neuropharmacology 2013, 64:240-247.

46. Gilmour G, Broad LM, Wafford KA, Britton T, Colvin EM, Fivush A, Gastambide F, Getman B, Heinz BA, McCarthy AP, Prieto L, Shanks E, Smith JW, Taboada L, Edgar DM, Tricklebank MD: In vitro characterisation of the novel positive allosteric modulators of the $\mathrm{mGlu}_{5}$ receptor, LSN2463359 and LSN2814617, and their effects on sleep architecture and operant responding in the rat. Neuropharmacology 2013, 64:224-239.

47. Rodriguez AL, Grier MD, Jones CK, Herman EJ, Kane AS, Smith RL, Williams R, Zhou Y, Marlo JE, Days EL, Blatt TN, Jadhav S, Menon UN, Vinson PN, Rook JM, Stauffer SR, Niswender CM, Lindsley CW, Weaver CD, Conn PJ: Discovery of novel allosteric modulators of metabotropic glutamate receptor subtype 5 reveals chemical and functional diversity and in vivo activity in rat behavioral models of anxiolytic and antipsychotic activity. Mol Pharmacol 2010, 78:1105-1123.

48. Liu CY, Jiang $X X$, Zhu YH, Wei DN: Metabotropic glutamate receptor 5 antagonist 2-methyl-6-(phenylethynyl)pyridine produces antidepressant effects in rats: Role of brain-derived neurotrophic factor. Neuroscience 2012, 223:219-224.

49. Tatarczyńska E, Klodzińska A, Chojnacka-Wójcik E, Palucha A, Gasparini F, Kuhn R, Pilc A: Potential anxiolytic- and antidepressant-like effects of
MPEP, a potent, selective and systemically active mGlu5 receptor antagonist. Br J Pharmacol 2001, 132:1423-1430.

50. Belozertseva IV, Kos T, Popik P, Danysz W, Bespalov AY: Antidepressant-like effects of mGluR1 and mGluR5 antagonists in the rat forced swim and the mouse tail suspension tests. Eur Neuropsychopharmacol 2007, 17:172-179.

51. Pietraszek M, Gravius A, Schäfer D, Weil T, Trifanova D, Danysz W: mGluR5, but not mGluR1, antagonist modifies MK-801-induced locomotor activity and deficit of prepulse inhibition. Neuropharmacology 2005, 49:73-85.

52. Li X, Need AB, Baez M, Witkin JM: Metabotropic glutamate 5 receptor antagonism is associated with antidepressant-like effects in mice. J Pharmacol Exp Ther 2006, 319:254-259.

53. Hashimoto K, Sawa A, lyo M: Increased levels of glutamate in brains from patients with mood disorders. Biol Psychiatry 2007, 62:1310-1316.

54. Sanacora G, Gueorguieva R, Epperson CN, Wu YT, Appel M, Rothman DL, Krystal JH, Mason GF: Subtype-specific alterations of aminobutyric acid and glutamate in patients with major depression. Arch Gen Psychiatry 2004, 61:705-713.

55. Hashimoto K: Emerging role of glutamate in the pathophysiology of major depressive disorder. Brain Res Rev 2009, 61:105-123.

56. Yan QJ, Rammal M, Tranfaglia M, Bauchwitz RP: Suppression of two major fragile $X$ syndrome mouse model phenotypes by the mGluR5 antagonist MPEP. Neuropharmacology 2005, 49:1053-1066.

57. Pop AS, Gomez-Mancilla B, Neri G, Willemsen R, Gasparini F: Fragile X syndrome: a preclinical review on metabotropic glutamate receptor 5 (mGluR5) antagonists and drug development. Psychopharmacology (Berl). in press.

58. Palucha A, Pilc A: Metabotropic glutamate receptor ligands as possible anxiolytic and antidepressant drugs. Pharmacol Ther 2007, 115:116-147.

59. Pecknold JC, McCLURE DJ, Appeltauer L, Wrzesinski L, Allan T: Treatment of anxiety using fenobam (a nonbenzodiazepine) in a double-blind standard (diazepam) placebo-controlled study. J Clin Psychopharmacol 1982, 2:129-133.

60. Berry-Kravis E, Hessl D, Coffey S, Hervey C, Schneider A, Yuhas J, Hutchison J, Snape M, Tranfaglia M, Nguyen DV, Hagerman R: A pilot open label, single dose trial of fenobam in adults with fragile X syndrome. J Med Genet 2009, 46:266-271.

61. Jacquemont $\mathrm{S}$, Curie A, des Portes $\mathrm{V}$, Torrioli MG, Berry-Kravis E, Hagerman RJ, Ramos FJ, Cornish K, He Y, Paulding C, Neri G, Chen F, Hadjikhani N, Martinet D, Meyer J, Beckmann JS, Delange K, Brun A, Bussy G, Gasparini F, Hilse T, Floesser A, Branson J, Bilbe G, Johns D, Gomez-Mancilla B: Epigenetic modification of the FMR1 gene in fragile $X$ syndrome is associated with differential response to the mGluR5 antagonist AFQ056. Sci Trans/ Med 2011, 3:64ra1.

62. Emmitte KA: mGlu 5 negative allosteric modulators: a patent review (2010-2012). Expert Opin Ther Pat 2013, 23:393-408.

63. Newell KA: Metabotropic glutamate receptor 5 in schizophrenia: emerging evidence for the development of antipsychotic drugs. Future Med Chem 2013, 5:1471-1474.

\section{doi:10.1186/1471-244X-14-23}

Cite this article as: Newell and Matosin: Rethinking metabotropic glutamate receptor 5 pathological findings in psychiatric disorders: implications for the future of novel therapeutics. BMC Psychiatry 2014 14:23

\section{Submit your next manuscript to BioMed Central and take full advantage of:}

- Convenient online submission

- Thorough peer review

- No space constraints or color figure charges

- Immediate publication on acceptance

- Inclusion in PubMed, CAS, Scopus and Google Scholar

- Research which is freely available for redistribution 